\title{
HETEROCHROMATIN, ABERRANT ENDOSPERM NUCLEI AND GRAIN SHRIVELLING IN WHEAT-RYE GENOTYPES
}

\author{
M. D. BENNETT \\ Plant Breeding Institute, Maris Lane, Trumpington, Cambridge CB2 2LQ
}

Received 1.iv.77

\begin{abstract}
SUMMARY
Evidence is presented leading to the conclusion that there is, in wheat-rye genotypes, a causal link first, between the presence of late replicating segments of heterochromatin on rye chromosomes and the occurrence of chromosome bridges at anaphase and of other aberrant nuclei in coenocytic endosperm, and second, between the frequency of occurrence of aberrant nuclei in young endosperms and the degree of grain shrivelling at maturity. Bridges in coenocytic endosperm of wheat-rye genotypes are caused at anaphase by the failure of rye chromosomes to separate at the telomeres where late replicating DNA is known to be located. The frequency of occurrence of aberrant nuclei in endosperms of the seven disomic chromosome addition lines of King II rye to Holdfast wheat fixed at the end of the coenocytic stage is significantly lower in three addition lines lacking a large telomeric block of terminal heterochromatin on one arm (due to its deletion) than in the remaining four addition lines without deletions of terminal heterochromatin. Evidence is presented showing a significant positive correlation between the proportion of aberrant nuclei in endosperms of six hexaploid triticales during the first 4 days after pollination, and the degree of grain shrivelling scored at maturity. It is concluded that the reduction or elimination of segments of late replicating DNA from rye chromosomes should be a major object in the breeding of economically useful triticales, and the means of achieving this goal are discussed.
\end{abstract}

\section{INTRODUGTION}

THE chromosomes of cultivated rye differ from those of tetraploid and hexaploid wheat both in the total amount of DNA, and in the amount of heterochromatin stained as G-bands, which they contain. Diploid rye ( $4 C$ nuclear DNA amount $=33.14 \mathrm{pg}$ ) contains about 33 per cent more DNA than the largest of the diploid genomes found in tetraploid and hexaploid wheat $(4 C=c .24 .9 \mathrm{pg})$. Moreover, rye chromosomes characteristically possess large C-bands at one or both telomeres, as well as some intercalary bands (Verma and Rees, 1974), while wheat chromosomes possess only minor C-bands at, or near, some of their telomeres, although they do possess small intercalary C-bands (Gill and Kimber, 1974). Telomeric heterochromatin in rye is late replicating at $S$ (Lima-de-Faria and Jaworska, 1972; Ayonoadu and Rees, 1973).

Hexaploid and octoploid triticales exhibit nuclear instability, having much higher univalent frequencies at metaphase I than either their wheat or rye parents, besides having aberrant nuclear development in their young endosperms (Bennett, 1973; Kaltsikes, Roupakias and Thomas, 1975) and, to varying degrees, shrivelled mature grain (Darvey, 1973). It has been suggested that nuclear instability in triticale both at meiosis and in young endosperm may result from the interaction of genomes which control or 
complete development at different rates at those stages in their wheat and rye parents (Bennett, Chapman and Riley, 1971 ; Bennett, Smith and Barclay, 1975 ), and that the cause of the different rates of development was primarily nucleotypic rather than genetic. Thus, it was suggested that "genome incompatibility in triticale, manifested both in meiocytes and coenocytic endosperm, is caused by the presencc of a large segment of late-replicating heterochromatin at the telomeres of rye chromosomes but not of the much smaller chromosomes of wheat" (Bennett, 1973). In particular it was suggcsted, first, that aberrant nuclei in coenocytic triticale cndosperm are normally caused by the late replicating segments of heterochromatin at the telomeres of the rye chromosomes; and second, that such aberrant nuclei are a major cause of shrivelled grain at maturity. This paper presents further evidence in support of these idcas.

\section{Materials and Methods}

(a) Materials

Twenty-one genotypes were used:

(i) Six hexaploid triticales $(2 n=6 x=42)$, "Rosner" (a Canadian variety), and "Cinnamon", TCL 3, TCL 4, TGL 19 and ITSN 30 (all originally derived from CIMMYT's triticale breeding programme in Mexico).

(ii) The seven wheat-rye disomic chromosome addition lines of " Holdfast" and "King II" $(2 n=6 x+2=44)$ produced at the Plant Breeding Institute (Riley and Chapman, 1958; Riley and Macer, 1966). Each addition line contains the 42 chromosomes of "Holdfast" wheat plus a different known pair of "King II " rye chromosomes (although three of the " King II" chromosomes (III, VI and VII) have been modified in the wheat background since the addition lines were first produced (Singh and Röbbelen, 1976)).

(iii) The scven wheat-rye monosomic chromosome addition lines of "King II " to hexaploid wheat $(2 n=6 x+1=43)$. These werc made in 1975 by crossing each of the seven disomic chromosome addition lines listed above with the hexaploid bread wheat variety "Cininese Spring", and selecting from the $\mathrm{F}_{1}$ progeny, plants with 43 chromosomes.

(iv) Secale cereale L. $(2 n=2 x=14)$ cv. "Petkus Spring".

\section{(b) Methods}

The six hexaploid triticales were grown in field plots in 1972, and samples of the grain recovercd. The degree of shrivelling in these samples was assessed visually by $\mathrm{Mr} \mathrm{R}$. S. Gregory and scored using a scale with 13 stcps (such that the more shrivelled the grain sample, the lower was the score given).

In the wintcr of $1973 / 74$ the same six triticales, and the scven HoldfastKing II disomic addition lines were grown in a glasshouse until development in leading tillcrs was about 1 week prior to meiosis in the anthers. They were then transferred to a growth room at $20 \pm 1{ }^{\circ} \mathrm{C}$ and given continuous light.

At lcast ten spikes of each triticale, and at least six spikes of each disomic 
addition line, were emasculated 2-3 days before anther dehiscence and 3-5 days later hand-pollinated with pollen from a plant of the same genotype. Spikes were fixed in 1:3 glacial acetic acid : ethanol at known intervals of up to 5 days after pollination. From 20 to 50 florets were examined in each genotype at each sampling time. The total number of endosperm nuclei or cells and the total number of aberrant endosperm nuclei in each floret was scored using Feulgen, aceto-carmine, or alcoholic carmine stained preparations of endosperms dissected out of single ovules as previously described (Bennett et al., 1975). The numbers and proportion of aberrant endosperm nuclei given in this paper were estimated using the same slides as were used to obtain the estimates of the total numbers of endosperm nuclei or cells per floret in the six triticales and seven disomic addition lines already published (Bennett et al., 1975).

Estimates of the proportion of aberrant endosperm nuclei were expressed in one of two ways. Sometimes the total percentage (T.P.) of endosperm nuclei was calculated. This involved summing the total numbers of endosperm nuclei and aberrant endosperm nuclei scored in all the florets fixed at a single time after pollination and expressing the latter as a percentage of the former, i.e. the number of aberrant nuclei per hundred endosperm nuclei. Otherwise the mean percentage of aberrant nuclei per floret (M.P.) was calculated. This involved first calculating the percentage of aberrant endosperm nuclei in each floret, and then taking the mean of these values for florets fixed at a single time after pollination.

Plants of each of the seven monosomic chromosome addition lines of " King II" were grown in a glasshouse and transferred to a growth room at $20 \pm 1{ }^{\circ} \mathrm{C}$ with continuous light about 1 week before meiosis occurred in leading tillers during the autumn and winter of 1975/76. Anthers were fixed in $1: 3$ glacial acetic acid : ethanol, hydrolysed for 10 minutes in $1 \mathrm{~N} \mathrm{HCl}$ at $60^{\circ} \mathrm{C}$, stained in Leuco-basic fuchsin ( $p \mathrm{H}$ adjusted to $3 \cdot 6$ ) for 2 hours, given three 10-minute washes in $\mathrm{SO}_{2}$ water, and squashed in 45 per cent acetic acid. The squash preparations were examined using an M86 Vickers integrating microdensitometer, and the DNA content of univalents was measured in suitable cells containing 21 bivalents and a single univalent (since in such cells the univalent is always a known King II addition chromosome). All DNA measurements were made within 5 hours of preparing the squashes and before fading could be detected.

\section{Results}

\section{(a) Bridges in wheat-rye endosperm}

A major class of aberrant nuclei in coenocytic endosperm of triticale and rye addition lines to wheat is undoubtedly caused by the failure to separate chromatids completely at anaphase, thus producing bridges which persist throughout interphase (Bennett, 1973). Cytological examination of Feulgen stained coenocytic endosperm in wheat-rye genotypes in the present work shows that such bridges are invariably caused by failure to separate chromatids at the telomere of one or both arms of the chromosome. This in itself suggests that the rye chromosomes are responsible, since the latest replicating DNA in wheat chromosomes is probably at the centromere, as indeed it is in rye, with the exception of the telomeric heterochromatin 
(Lima-de-Faria and Jaworska, 1972). This conclusion was verified by observations of bridges in triticale endosperm after Giemsa staining (fig. 1). These showed that bridges were formed of rye chromosomes, although apparently arms with or without large segments of telomeric heterochromatin were involved.

\section{(b) $4 \mathrm{G}$ DNA content of "King II" rye addition chromosomes}

The relative $4 C$ DNA contents in arbitrary units (a.u.) of the seven "King II" addition chromosomes are given in table 1. These ranged from a minimum of 3.83 a.u. in chromosome III to $4.96 \mathrm{a} . \mathrm{u}$. in chromosome

\section{TABLE 1}

The relative 4C D.NA contents of the seven addition chromosomes of "King II" (in arbitrary units)

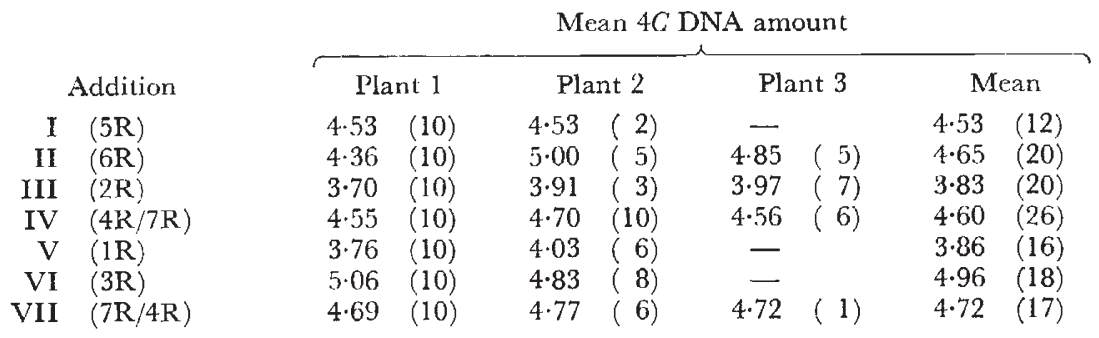

$\mathcal{N} . B$. - The number of univalents measured in each squash is given in brackets.

VI. Analysis of variance revealed significant differences both between addition lines $(\mathrm{P}=<0.01)$, and between plants within addition lines $(\mathbf{P}=<0.001)$. However, there was significant variation between addition lines over and above that between plants within lines (table 2). The mean estimates for addition II plants were much more variable than for any other addition line (table 1), which suggests that the significant differences between plants within lines might be accounted for by variation between estimates for this chromosome. This was confirmed by further analysis, omitting the

TABLE 2

Analysis of variance for estimates of the $4 \mathrm{C} D \mathcal{N A}$ content of the seven King II addition chromosomes given in table 1

\begin{tabular}{lrrrrc}
\multicolumn{1}{c}{ Item } & S.S. & d.f. & M.S. & V.R. & P \\
Total & 33.26 & 128 & - & - & - \\
Addition lines & 15.99 & 6 & 2.665 & 7.593 & $* *$ \\
Plants within lines & 3.75 & 11 & 0.351 & - & -
\end{tabular}

results for addition chromosome II, which showed highly significant differcnces between addition lines $(P=<0.001)$ but no significant differences betwcen plants within addition lines. Whether the variation between estimates of $4 C^{V}$ DNA content of addition II in different plants is real, or due to error, is unknown. However, in view of the variation between plants the estimates for the DNA content of this addition chromosome must bc viewed with caution until further measurements have been made. 


\section{(c) Aberrant nuclei in Holdfast-King II addition line endosperms}

Table 3 gives the total percentage of aberrant nuclei in endosperms fixed at 1, 2 and 3 days after pollination, i.e. at early, mid and late coenocytic stage. Comparing these data with total DNA amount per addition line chromosome (from table l) showed no significant relationship between these two characters at any time.

Comparison of the C-banding patterns for the chromosomes of King II rye with those of the seven King II addition chromosomes to Holdfast has shown that three of the seven rye chromosomes in the addition lines have deletions (Singh and Röbbelen, 1976), namely, additions III, VI and VII. In each case the deletion involved the loss of a segment bearing a large telomeric C-band (from the short arm of additions III and VI, and the long

TABle 3

The total percentage of aberrant nuclei in endosperms of the seven disomic addition lines of HoldfastKing II at 1, 2 and 3 days after pollination

\begin{tabular}{|c|c|c|c|c|c|c|c|}
\hline & & & & te & llinati & days & \\
\hline & Addition & & 1 & & 2 & & 3 \\
\hline I & $(5 R)$ & $0 \cdot 0$ & $(15 \cdot 2)$ & 0.63 & (204) & 0.51 & (1523) \\
\hline II & $(6 \mathrm{R})$ & $0 \cdot 0$ & $(14.9)$ & $0 \cdot 10$ & $(263)$ & $1 \cdot 30$ & (1529) \\
\hline III & (2R) & $1 \cdot 25$ & $(20 \cdot 0)$ & $0 \cdot 17$ & $(276)$ & 0.28 & (2045) \\
\hline IV & $(4 \mathrm{R} / 7 \mathrm{R})$ & 0.76 & $(17 \cdot 4)$ & 0.47 & (293) & $2 \cdot 75$ & (1109) \\
\hline V & (1R) & 0.0 & $(8.4)$ & 1.69 & $(217)$ & $1 \cdot 05$ & (1037) \\
\hline VI & $(3 \mathrm{R})$ & $0 \cdot 0$ & (14.9) & 0.59 & $(150)$ & $0 \cdot 13$ & ( 907) \\
\hline VII & $(7 R / 4 R)$ & 0.0 & $(13 \cdot 3)$ & $0 \cdot 69$ & (194) & $0 \cdot 20$ & ( 824) \\
\hline
\end{tabular}

N.B.-The mean number of enodsperm nuclei or cells per floret is given in brackets-taken from Bennett et al. (1975).

arm of addition VII). It is, therefore, interesting to compare the percentage of aberrant nuclei in endosperms of addition lines with and without deletions. Making this comparison for endosperms fixed at early and mid-coenocytic stages when the mean number of endosperm nuclei per floret is low, reveals no significant difference. However, making the comparison for endosperms fixed 3 days after pollination, at the end of the coenocytic stage when the number of endosperm nuclei or cells is much higher, shows a striking difference. Thus, the percentage of aberrant nuclei in the three addition lines with deletions ranged from 0.13 to 0.28 (mean 0.20 ), while in the four addition lines without deletions it ranged from 0.51 to 2.75 (mean 1.40), and this difference was significant $(P=<0.05)$.

As shown above, the proportion of aberrant nuclei is not related to the total DNA amount per addition chromosome. Therefore, the significantly lower proportion of aberrant endosperm nuclei in the addition lines with deletions is unlikely to be associated with the decrease in total DNA amount due to the deletion, although it does appear to be associated with the loss of the particular DNA associated with those deletions, i.e. the loss of telomeric heterochromatin. Thus, it appears that the presence of telomeric heterochromatin is a major cause of aberrant endosperm nuclei, as was previously suggested (Bennett, 1973). 


\section{(d) Aberrant nuclei and grain shrivelling in triticales}

Analysis showed a significant relationship between mean pcrcentage of aberrants and grain shrivclling for endosperms fixcd 4 days after pollination $(\mathrm{P}=<0 \cdot 05)($ table 4$)$.

\section{TABLE 4}

The mean percentage per floret (M.P.), of aberrant nuclei in endosperms of triticales fixed at 1, 2, 3 or 4 days afler pollination

\begin{tabular}{|c|c|c|c|c|c|c|}
\hline \multirow[b]{2}{*}{ Genotype } & \multirow{2}{*}{$\begin{array}{c}\text { Grain } \\
\text { shrivelling } \\
\text { score }\end{array}$} & \multicolumn{5}{|c|}{ Time after poilination/days } \\
\hline & & 1 & 2 & 3 & & 4 \\
\hline Rosner & 7 & $0.00 \quad(9 \cdot 6)$ & $0.28 \quad$ & $3.76 \quad(591)$ & $3 \cdot 45$ & (3414) \\
\hline Cinnamon & 5 & $0.34(14.5)$ & $0.96(213)$ & $2 \cdot 82(1007)$ & 9.04 & (3139) \\
\hline TCL 3 & 4 & $3.40(11.3)$ & $1.69(138)$ & $2.54 \quad(840)$ & $9 \cdot 48$ & (2794) \\
\hline TCL 4 & 6 & $0.37(15.7)$ & $8.06(171)$ & 0.89 (1108) & $2 \cdot 61$ & (4675) \\
\hline TCL 19 & 9 & $0.42(14.7)$ & $1.04(145)$ & $1.43(648)$ & $3 \cdot 71$ & (3470) \\
\hline ITSN 30 & 10 & $0.00 \quad(6.6)$ & $0.78(147)$ & $0.96 \quad(842)$ & 0.97 & (2662) \\
\hline
\end{tabular}

N.B.-The mean number of enclosperm nuclei or cells per floret is given in bracketstaken from Bennett et al. (1975).

It should be noted that, provided aberrant nuclei once formed continue to undergo rounds of DNA synthesis synchronously with adjacent normal cndosperm nuclei, they will continue to contain a constant percentage of the total DNA content of the cndosperm, although, owing to their failure to divide at mitosis, they will occupy a progressively smaller percentage of the total number of nuclei or cells in the endosperm. Thus in theory, the highest single percentage of abcrrant nuclei scored at any time during the coenocytic stage is, in terms of the proportion of the total DNA per endosperm, a good indication of the degree of aberrancy continuing until its end. However, in practice estimates of the percentage of aberrant nuclei in florets fixed I day after pollination should be cxcluded from such comparisons because they are subject to much greater error than estimates made at later stages. Day-old endosperms contain a very low number of nuclei (tables 3 and 4) so that small differences due to sampling error in the number of aberrant nuclei scored result in an unduly large variation in the estimated percentage of aberrant nuclei when small samples of florets are used. In the present work cstimates of the mean percentage of abcrrant nuclei were greatly reduced in cellular endosperms of all six triticales fixed 5 days after pollination compared with those fixed 1 day earlicr. Comparing the highest mcan percentage of aberrant nuclei for cach triticale during the period 2 to 4 days after fertilisation with grain shrivclling at maturity gave a high negative correlation coefficient $(r=-0.95)$. Analysis showed a highly significant $(\mathrm{P}=<0.01$ ) relationship between the two characters.

Taken together these rcsults indicate that there is in general a positive correlation between the occurrence of aberrant nuclei in early endospcrm development and the degree of grain shrivelling seen at maturity.

\section{Discussion}

It was previously shown that bridges produced at anaphase, and remaining unbroken throughout interphase, are a major cause of progrcssive 

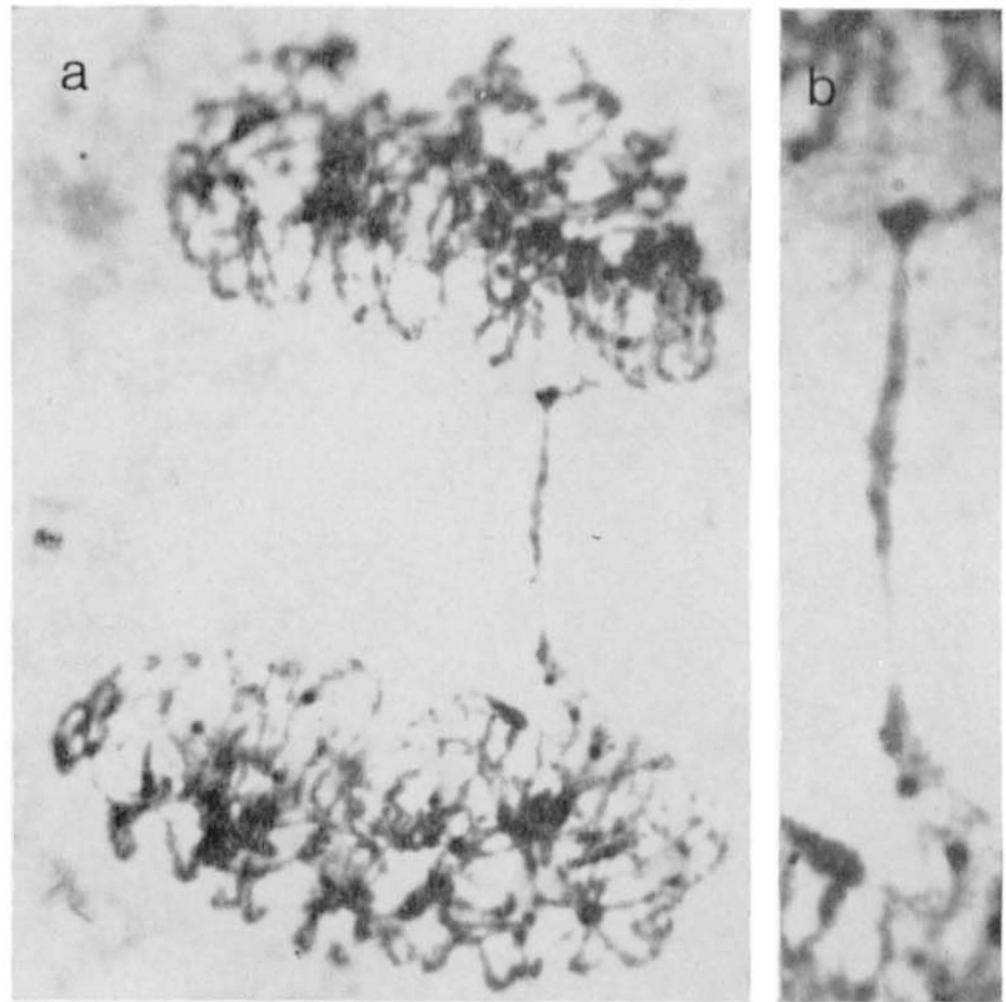

FiG. 1.-An aberrant endosperm nucleus in "Rosner" triticale showing a bridge caused by failure to separate chromatids at a telomere of a rye chromosome identified by C-banding after Giemsa staining. $(a) \times 1000,(b) \times 2000$. 
aberrant nuclear development in coenocytic endosperm of wheat-rye genotypes (Bennett, 1973). This paper presents cytological evidence showing that such bridges result from the failure of rye chromosomes to separate at one or both telomeres.

The present results show a significantly lower percentage of aberrant nuclei in rye addition lines with the deletion of terminal C-bands than in addition lines without such deletions. They also show significant positive correlations between the percentage of aberrant nuclei in young endosperms and the degree of shrivelling in mature grain of hexaploid triticale. Thus, they strongly support the idea that, in genotypes with wheat and rye chromosomes, most of the aberrant nuclei in young endosperms are caused by late replicating telomeric heterochromatin, and that aberrant nuclei are a major cause of grain shrivelling, as first suggested by the present author (Bennett, 1973).

A positive relationship between the occurrence of aberrant endosperm nuclei and kernel shrivelling has been established previously in both triticales (Kaltsikes et al., 1975), and in wheat-rye addition and substitution lines (Kaltsikes and Roupakias, 1975). However, Kaltsikes and Roupakias (loc. cit.) concluded that large blocks of telomeric heterochromatin have no effect on the number of aberrant nuclei formed when rye chromosomes are added to the wheat complement. This conclusion, the opposite of that reached in the present work, was reached using several of the same Holdfast-King II disomic chromosome addition lines and scoring for the same characters as the present work. It is therefore necessary to consider the reason for the two different conclusions.

Kaltsikes and Roupakias (1975) examined only four of the seven complete disomic chromosome additions for Holdfast-King II studied in the present work, namely, additions II (6R), III (2R), IV (4R) and VII (7R). As noted elsewhere, Singh and Röbbelen (1976) have shown that two of these four addition chromosomes (III (2R), and VII (7R)) have lost terminal G-bands. However, Kaltsikes and Roupakias were unaware of this, and so they mistakenly asserted that both these chromosomes carry major terminal heterochromatic bands, basing this claim on the karyotype for HoldfastKing II disomic chromosome addition lines published by Darvey and Gustafson (1975). A re-examination of the slides used to prepare fig. I in Darvey and Gustafson (1975) has confirmed that the examples of chromosomes $2 \mathrm{R}$ and $7 \mathrm{R}$ were taken from King II rye, and not from the respective Holdfast-King II addition lines (Gustafson, personal communication). Once allowance is made for the deletions involving the loss of terminal $\mathrm{G}$-bands on King II additions III and VII, the results given by Kaltsikes and Roupakias for Holdfast-King II additions, like the present results, fully support the idea of a positive correlation between the presence of telomeric heterochromatin and the occurrence of aberrant nuclei in young endosperm. Thus, the number of aberrant nuclei per thousand endosperm nuclei in the two addition lines with deletions (III and VII) was $3 \cdot 7$ and $1 \cdot 5$, respectively; while in the two addition lines without deletions (IV and II) it was $9 \cdot 6$ and 29.1, respectively (Kaltsikes and Roupakias, 1975).

There is now considerable evidence showing that nuclear instability in triticale is associated with the presence of large segments of heterochromatin at the telomeres of rye chromosomes, both during meiosis (Merker, 1976; Thomas and Kaltsikes, 1976) and during early endosperm development. 
Consequently, the reduction or climination of these segments should be one prime object in breeding economically uscful triticalcs. Already, by selecting for good fertility and non-shrivelled grain, plant breeders have unwittingly made some progress in this direction. 'Thus, several improved triticales contain rye chromosomes modified by the loss, or reduction in size, of terminal C-bands (Gustafson and Bennett, 1976; Gustafson, personal communication). However, many others contain pairs of wheat D-genome chromosomes substitutcd for one or more pairs of rye chromosomes (Gregory, 1973; Gustafson and Zillinsky, 1973; Merker, 1975), and their selection has involved an uncontrollcd loss of many of the rye genes which make triticale desirable.

If the full potential of the rye genotype is to be realised, then triticales with all seven pairs of rye chromosomes must be produced. As plant brecders seem unable to distinguish between improvement associated with wheat-rye substitutions, and improvement due to reduced heterochromatin on modified rye chromosomes, routine screening of brceders' material using C-banding techniques seems essential if this objective is to bc consistently attained. While this may be impractical using slow traditional methods, it should be feasible using automated methods like those recently developed for human chromosomes (Lubs and Ledley, 1972; Castleman and Wall, 1972). Prolonged selection within a single triticale line should yield individuals with little or no telomeric heterochromatin, but these would have a very limited potential for further exploitation. For example, they could not be crosscd with normal triticales without regaining rye chromosomes with telomeric heterochromatin. Thus, their further selection would be restricted to a narrow genetic base. This problem could be overcome by selecting a complete modified rye genome in several triticales derived from crosses between different wheat and rye parents. Intcrcrossing these would then provide the source of genetic variation for further brecding. An alternative and less demanding approach would be to utilise existing modificd rye chromosomes in triticales. This would involve, first, screening triticales and identifying examples of each rye chromosome modified by the loss of telomeric heterochromatin. Second, triticales containing different known modified rye chromosomes would be crossed and plants containing all the modified chromosomes present in both parents selected from the progeny. This would be repeated until individuals containing seven pairs of modified rye chromosomes were obtained. This approach should allow many triticales with little or no telomeric heterochromatin to be produced in a reasonably short time, while providing a wide genetic base for further breeding. Moreover, by selfing plants with one or more known modified rye chromosomes a collection of lines containing desirable, but incomplete, combinations of modified rye chromosomes could be maintained for future use.

\section{REFERENCES}

AYUNOADU, U., AND REES, H. 1973. DNA synthesis in rye chromosomes. Heredily, 30, 233-240.

RFNNETT, M. D. 1973. Meiotic, gametophytic and carly endosperm development in Triticale. In Triticale, eds R. MacIntyre and M. Campbell, pp. 137-148. IDRC, Ottawa.

BENNETT, M. D., CHAPMAN, V., AND RIIEY, R. 1971. The duration of meiosis in pollen mother cells of wheat, rye and Triticale. Proc. Roy. Soc. Lond. B., 178, 259-275. 
BenNeTt, M. D., SMith, J. B., AND Barclay, I. R. 1975. Early seed development in the Triticeae. Phil. Trans. Roy. Soc. Lond. B., 272, 199-227.

CASTlEman, K. R., AND WAll, R. J. 1972. Automatic systems for chromosome identification. In Chromosome Identification, eds T. Casperson and L. Zech, pp. 77-84. Academic Press, New York and London.

DARVEY, N. L. 1973. Genetics of seed shrivelling in wheat and triticale. In 4th International Wheat Genetics Symposium, pp. 155-159.

DARVEY, N. L., AND GUSTAFSON, J. P. 1975. Identification of rye chromosomes in wheat-rye addition lines and triticale by heterochromatin bands. Crop Sci., 15, 239-243.

Gill, B. S., AND Kimber, G. 1974. Giemsa C-banding and the evolution of wheat. Proc. Nat. Acad. Sci. USA, 71, 4086-4090.

GREGORY, R. s. 1973. Triticale research program in the United Kingdom. In Triticale, eds R. MacIntyre and M. Campbell, pp. 61-67. IDRC, Ottawa.

GUSTAFSON, J. P., AND ZILlinsky, F. J. 1973. Identification of D-genome chromosomes from hexaploid wheat in a 42-chromosome triticale. Proc. 4th Int. Wheat Genet. Symp., Mo. Agric. Exp. Stn., Columbia, Mo., pp. 225-232.

gUSTAFson, J. P., AND BENNETT, M. D. 1976. Preferential selection for wheat-rye substitutions in 42-chromosome triticale. Crop Sci., 16, 688-693.

KAltsikes, P. J., AND ROUPAKIAS, D. G. 1975. Endosperm abnormalities in Triticum-Secale combinations. II. Addition and substitution lines. Can. F. Bot., 53, 2068-2076.

KAltsikes, P. J., Roupakias, D. G., AND thomas, J. B. 1975. Endosperm abnormalities in Triticum-Secale combinations. I. Triticosecale and its parent species. Can. F. Bot., 53, 2050-2067.

LIMA-DE-FARIA, A., AND JAWORSKA, H. 1972. The relationship between chromosome size gradient and the sequence of DNA replication in rye. Heredity, 70, 39-58.

LUBS, H. A, AND LEDLEY, R. S. 1972. Automated analysis of differentially stained human chromosomes. In Chromosome Identification, eds T. Casperson and L. Zech, pp. 61-76. Academic Press, New York and London.

MERKER, A. 1975. Chromosome composition of hexaploid triticale. Hereditas, 80, 41-52. MERKER, A. 1976. The cytogenetic effect of heterochromatin in hexaploid triticale. Hereditas, 83, 215-222.

RILEY, R., AND CHAPMAN, v. 1958. The production and phenotypes of wheat-rye chromosome addition lines. Heredity, 12, 301-315.

RILEY, R., AND MACER, R. C. F. 1966. The chromosomal distribution of the genetic resistance of rye to wheat pathogens. Can. 7. Genet. Cytol., 8, 640-653.

SINGH, R. J., AND RÖBBELEN, G. 1976. Giemsa banding technique reveals deletions within rye chromosomes in addition lines. Z. Pflzücht., 76, 11-18.

THOMAS, J. B., AND KALTsikes, P. J. 1976. The genomic origin of the unpaired chromosomes in triticale. Can. 7. Genet. Cytol., 18, 687-700.

VERMA, s. C., AND REES, H. 1974. Giemsa staining and the distribution of heterochromatin in rye chromosomes. Heredity, 32, 118-122. 